\title{
Representation vs. Ideation in the Architectural Design Process
}

\author{
By Levent Kara*
}

While using catalysts from various cultural modalities has been a common practice in architectural design since the 1980's, the epistemic grounds of this practice and its pedagogical implications remain yet to be fully analyzed. The mainstream arguments in favor of using catalysts from other fields of culture in the making of architecture usually advance a sense of autonomy of the architectural design process in the construction of our cultural reality. However, a critical examination of the use of non-architectural cultural artifacts as generative devices in the architectural design process leads not only to an understanding of architectural making as a specific medium of intentionality, but also underlines the organic embeddedness of this intentional modality within a broader space of experience. The following study critically presents a design studio project that involves the translation of a filmic narrative into architectural spaces and places and articulates upon a notion of thinking in the architectural making as producing new nodes in our texture of experiential reality.

\section{Introduction}

While using catalysts from various cultural modalities has been a common practice in architectural design since the 1980's, the epistemic grounds of this practice and its pedagogical implications remain yet to be fully analyzed. The mainstream arguments in favor of using catalysts from other fields of culture in the making of architecture usually advance a sense of autonomy of the architectural design process in the construction of our cultural reality. However, a critical examination of the use of non-architectural cultural artifacts as generative devices in the architectural design process leads not only to an understanding of architectural making as a specific medium of intentionality, as the mainstream arguments conclude, but also underlines the organic embeddedness of this intentional modality within a broader space of experience, thus within the broader space of cultural making. In our firstperson phenomenal experience, various works of art and culture stand in different experiential modalities. However, the possibility of translations between these, in particular the possibility of interpreting different cultural artifacts into architectural space and place, also points to a common ground of spatio-temporal consciousness that holds various modes of experience and media of intentionality together. The following study critically presents a design studio project that involves the translation of a filmic narrative into

\footnotetext{
${ }^{*}$ Assistant Professor, University of South Florida, USA.
} 
architectural spaces and places. The interpretation of a film to generate architectural work is conducted through a series of mappings that unfold the different modalities of experience explored by the filmic tectonics onto two and three dimensional spatial constructs. The analysis of this design process is used to articulate a conceptual space for the notion of architectural making as a speculative act of thinking and making that forms new pieces of reality through an imaginative interpretation that projects possibilities out of the existing texture of culture.

\section{Going beyond Place as Metaphor: Two Tales of Image}

The narrative catalysts employed in the architectural process are an effective way of going beyond the learned habits of making architecture as an uncritical mimesis of history or tradition. Their value as generative devices, in the service of finding new ways of framing reality in the architectural constructs, is their ability to help re-formulate the design question through a new mode of thinking, the notion of place that injects an overall imagistic modality in the design process beyond habitual ways of the seeing and making place. This modality may be called a vision, in the best sense of the term, that holds the architectural object together as a distinct condition in the texture of life, lived through first-person experience beyond a familiarity with established forms of architecture. This vision that unifies the architectural construct in its making by guiding the decisions in the design process is a construction of imagination. It is an image: an ensemble of things and events, associations and projections. In this sense, the architectural image is the projection of a possible ensemble of life situations out of, but beyond, what exists.

Within this context of using narrative catalysts to project an architectural image that guides the design process, I delineate two different senses of image. On the one hand, there is a conception of the architectural image as a representational / symbolic device that constructs the experience of the subject through associations to known architectural forms and elements. What holds the architectural object in its unity is a mental image that constructs itself on the basis of other mental images acquired through exposure to some particular architectures in some particular ways of life. In this sense, the experience of space and time through the architectural object is a second order experience only given on an existing order of things. This is not different from linguistic experience. Words organize our thinking, thus space and time, through references to other words within a dictionary (an existing order of things). Consider what happens when you hear an utterance in the familiarity of a language which is a system of signs that do not have a phenomenal relation to their referents. Our relation to words is a socio-historical contract that we learn 
through being born into a language (an existing order of things). This sense of architectural images puts a referential hinge on the architectural form. ${ }^{1}$

\section{Making Place-Events: Cinematic Speculations ${ }^{2}$}

Operating under the premise of using cultural catalysts in the architectural design process as a way of constructing place-events, the following studio exercise explored meaningful ways of projecting architectural spaces that emerge out of a filmic narrative. Through the interpretations of the narrative and structural conditions of a film, the exercise sought for construction of architectural images with specific experiential qualities. The students were asked to study a foreign film ${ }^{3}$ as if it is a found object, without any subtitles, in order not to concern with the linguistic story in its completeness. The aim was to focus on the filmic strip as a cultural construction in itself, hence, on the specifically filmic choreography that weaves the cultural narrative beyond spoken words.

The film, with a photographic reference to memory, consisted of a series of distinct episodes, which are place-time bound, and shorter transitions between these (Figure 1). While viewing the film, the students were asked to pay close attention to the multiple camera angles strategically chosen to construct the layering of episodic place-events and the characters' inner worlds. Of particular importance for us in our speculative readings of the film were the following interrelated parameters:

1. Spatio-temporal distinctions: in-out/scale/vertical-horizontal/timespace/ intersection-threshold-boundary.

2. The moving frame sequence and the narrative (story as one imagines it).

3. Characters' stream of consciousness.

4. Concealing-revealing, presence-absence, of things, characters, visions.

5. Gaze, parallax, act of framing and layering information on a filmic strip:

- camera movements (spatial and focal), angle of views,

- movement as measure, movement as making space, movement as revealing

- body-vision-camera dialogues,

1. Juhani Pallasmaa, The Geometry of Feeling: A Look at the Phenomenology of Architecture Theory 1965-1995, ed. Kate Nesbitt (New York: Princeton Architectural Press, 1996), 449. "Form only affects our feeling through what it represents."

2. Igor Stravinsky, Poetics of Music in the Form of Six Lessons (Cambridge: Harvard University Press, 1947), 28. Speculation is used here in reference to Igor Stravinsky's idea of poetic making as speculation, "The phenomenon of music is nothing more than a phenomenon of speculation. There is nothing in this expression that should frighten you. It simply presupposes that the basis of musical creation is a preliminary feeling-out, a will moving first in an abstract realm with the object of giving shape to something concrete"

3. The Return, 2003, by Andrei Zvyagintsev. 
- reciprocity of things, characters, visions, movements.

6. Light/texture/space: the materiality of the filmic image.

7. The score and its relation to the moving image.

Thus, our objective was to unfold the construction of the filmic tectonic beyond the literary narrative, focusing on how the events of the movie were embedded and depicted through the construction of certain spatial conditions between objects and people and between people. Our initial studies were line mappings that discussed, almost literally, the construction of the episodic places in terms of the parameters listed above (Figures 2-4). Our second iteration was collage studies that explored the construction of events and places through camera angles, pace of the moving image, and even color and score as a distinct phenomenal experience of being in some place in some situation (Figure 5).
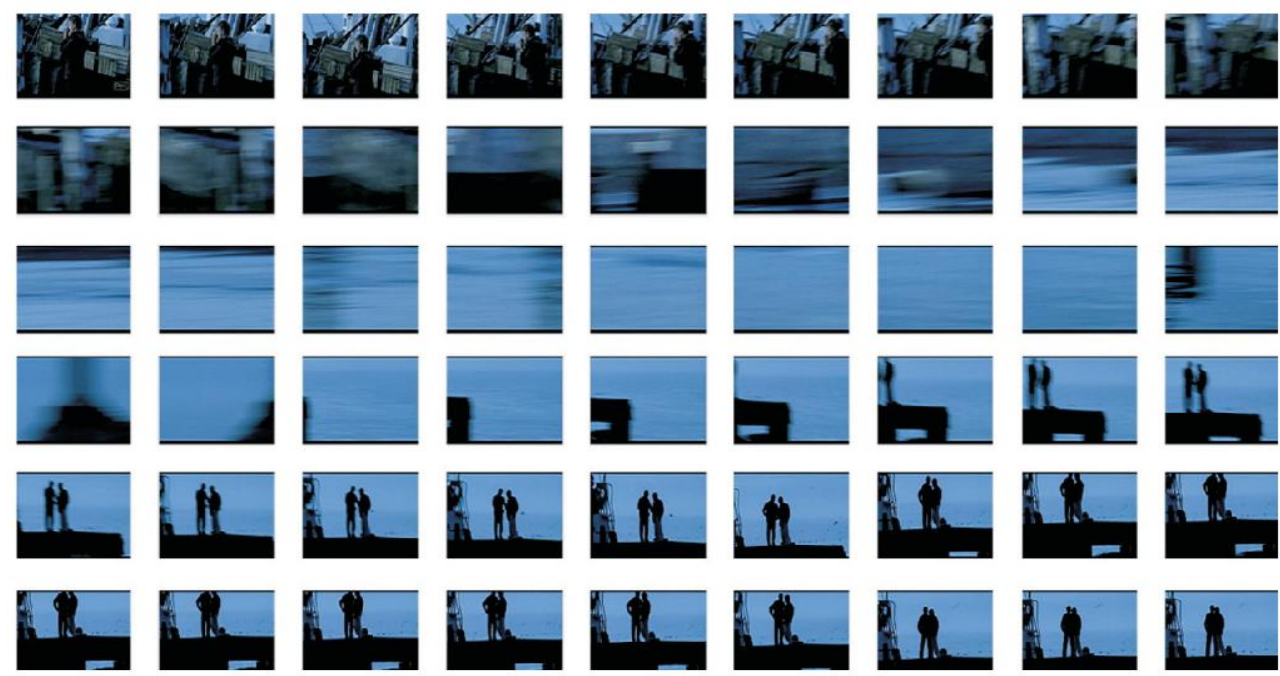

Figure 1. The Tectonics of the Filmic Strip: Making Place

Source: Author 



Figure 2. Mapping the Episodic Places: From Filmic Construct to Architectural Form Source: Author 
Vol. 2, No. $1 \quad$ Kara: Representation vs. Ideation in Architectural Design Process
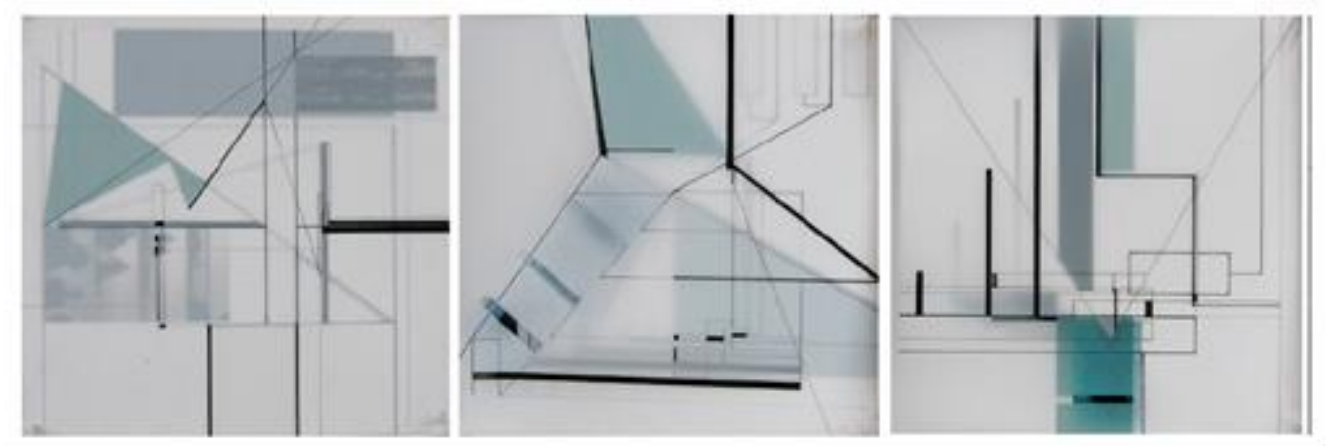

Figure 3. Diagrammatic Evolution of Place-Events 1: Reconstructing a Spatial Matrix

Source: Author
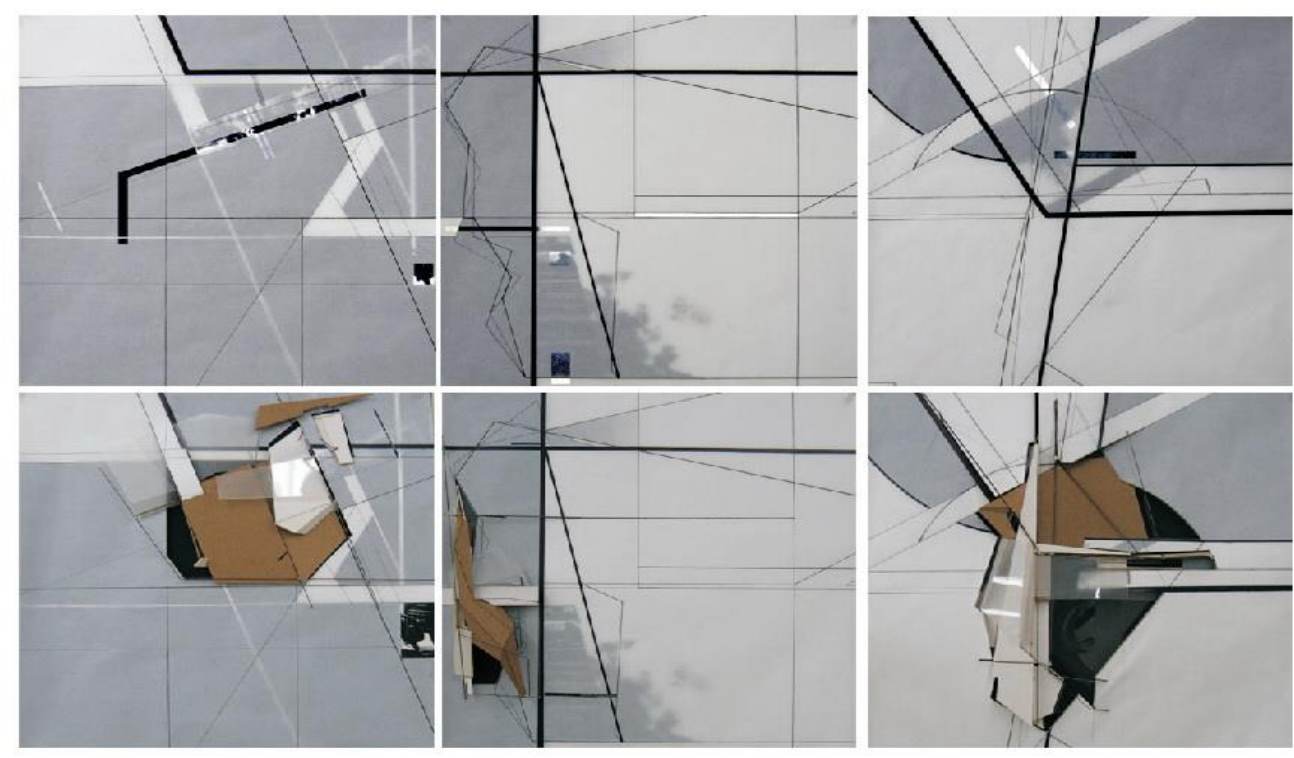

Figure 4. Diagrammatic Evolution of Place-Events 2: Refining the Spatial Matrix

Source: Author
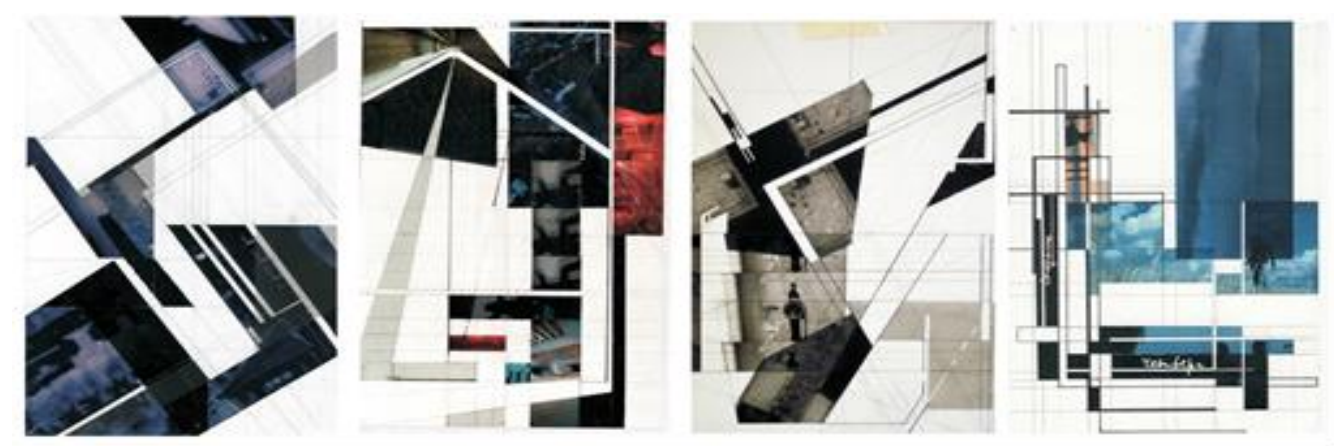

Figure 5. Collage Studies on the Phenomenology of Place-Events: Juxtaposing Spatial Matrix with Narrative Source: Author 
These second diagrams were more about capturing the phenomenal unity of places and events as they are constructed in time and space through various experiential modalities. In this sense, they were beyond any literal depiction of place-events in terms of plans, sections or elevations, as was mostly the case with the first series of line mappings which were now sublimated within this second iteration. These latter diagrams can be understood as notational devices that could be translated into architectural possibilities in terms of the experiential content they embody without specifying a context of meaning or scale yet. They are at the edge of architecture, but not architecture yet. In the multiplicity of their synthetic references, they project architectural images, some being-in-such-and-such-a-condition, before the concretization of architectural forms or objects.

With this in mind, our next step was to look at projections of possible plan and section ideas for a construct-to-come out of these diagrams that will carry the experiential qualities of the interpreted episodes/scenes. At this moment in the exercise, our relation to the diagrams split into two related but distinct contexts of meaning. First, they were to be looked at as tectonic entities that could ground a three-dimensional construct as to its spatial-volumetric narrative. Second, they were to be interpreted as material narrative conditions that could ground the occupational narrative of the three dimensional construct, beyond its overall spatial-volumetric systemicness, in terms of the relative sense of scales and enclosures, changing degrees of transparency and layeredness, thus changing degrees of movement, vision, and light conditions, and phenomenal experience.

We started with a series of sketching exercises to ground the construct-tocome in the systemicness of the interpretative diagrams (Figures 6-7). These sketches gave us the departure point for small physical models that discussed series of volumes in different scales and possible movement relations between them. These small models were studied in three phases of planar construction, linear construction, and a combination of linear and planar construction. The objective for this phasing was to control the relevance of the volumetric entities in an overarching unity of systemic relations, in an armature unifying the collective spatial definition, without losing their scalar and hierarchical identity (Figure 8). 

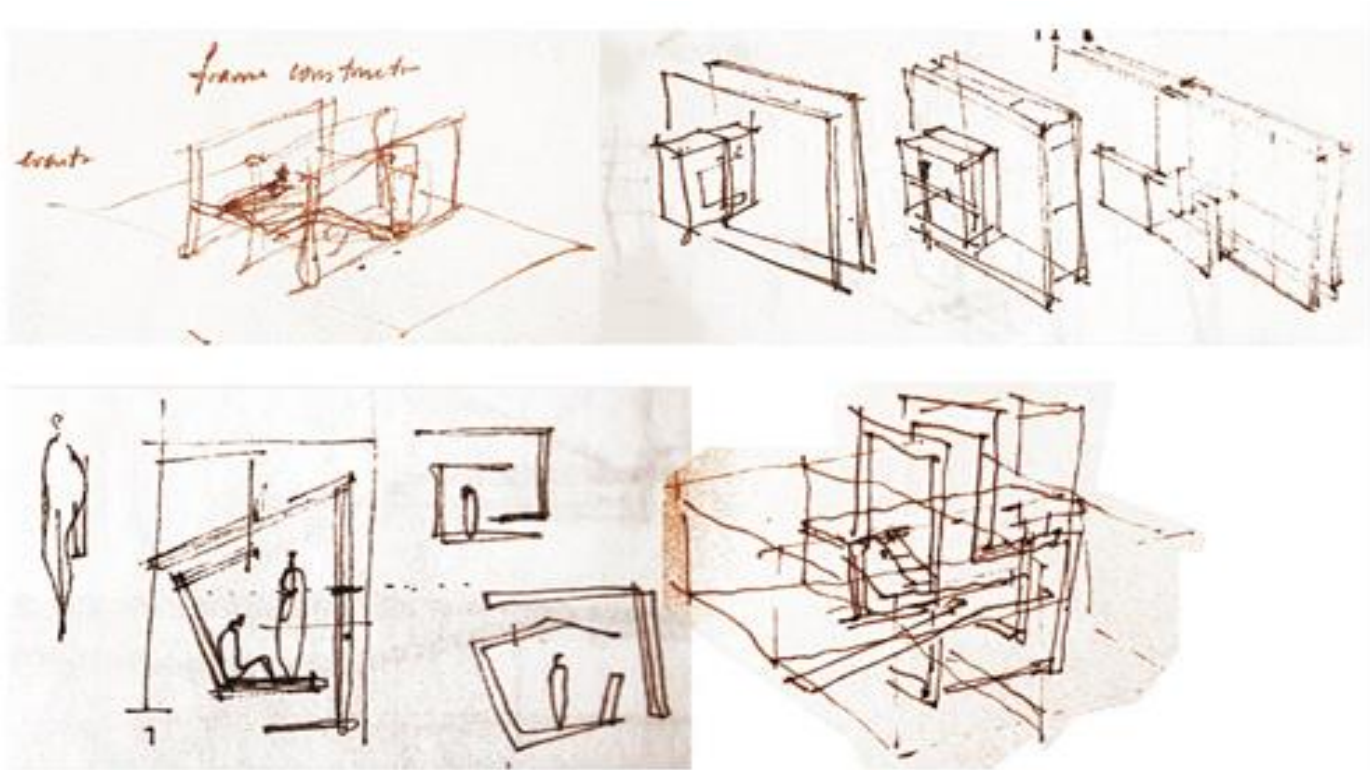

Figure 6. Thinking the Architecture-to-Come: Sketches 1: From Spatial Matrix to Volumetric Matrix

Source: Author
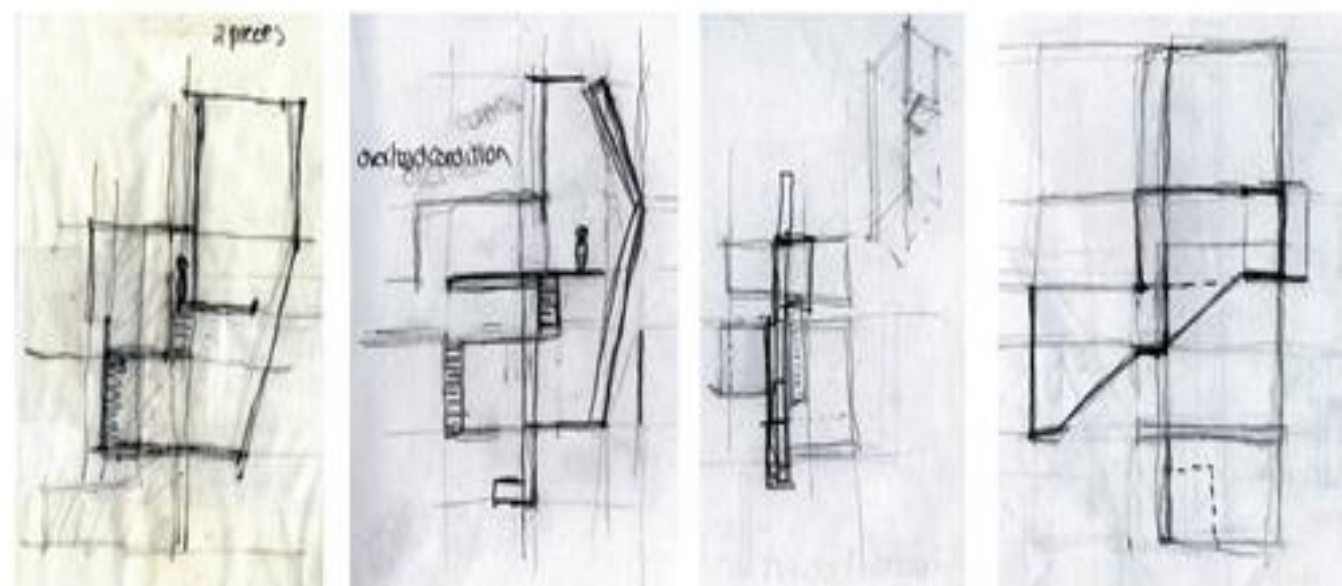

Figure 7. Thinking the Architecture-to-Come: Sketches 2: Examining

Movement

Source: Author 

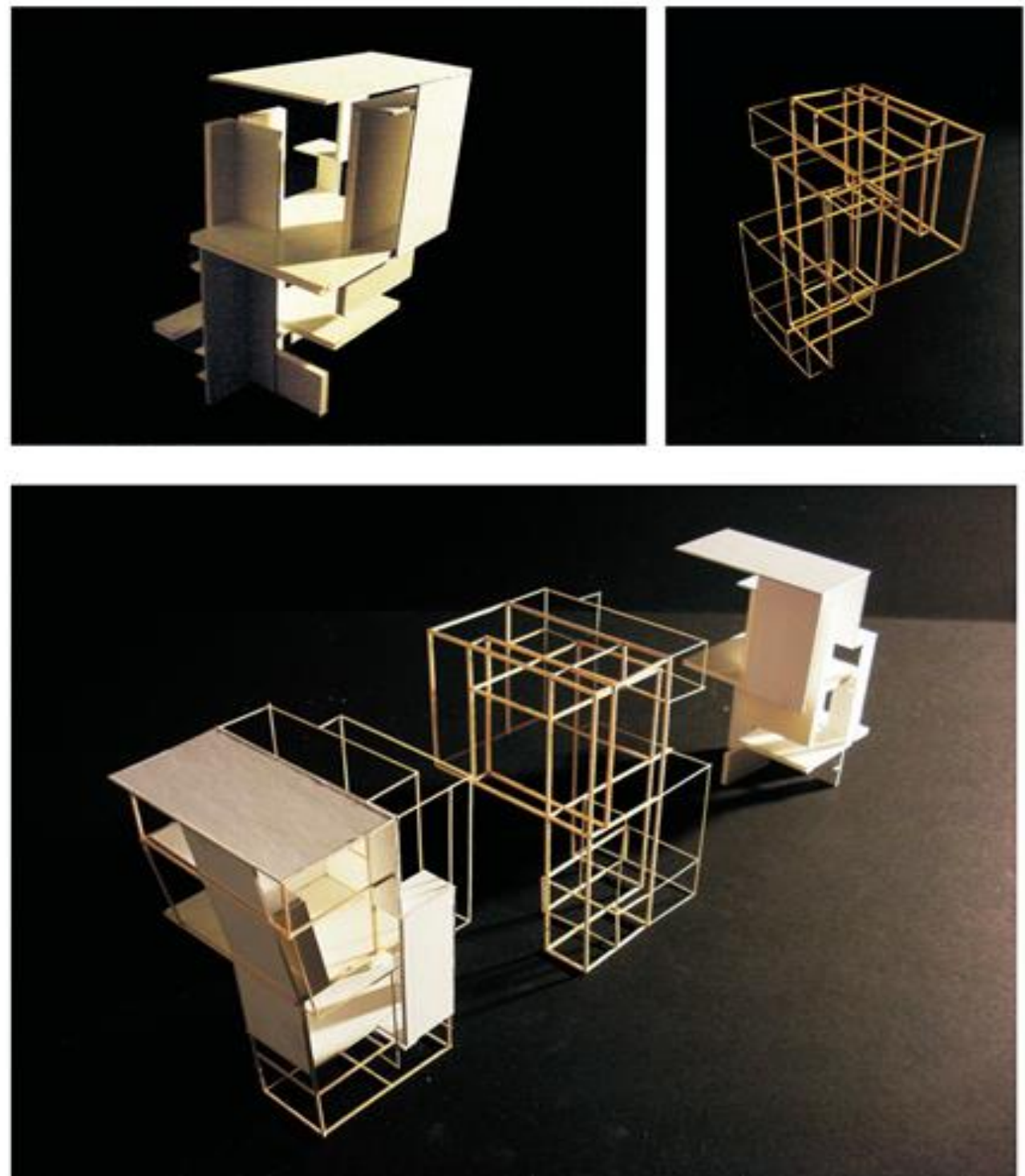

Figure 8. Thinking the Architecture-to-Come: Systemic Constructs Source: Author

Our final step was to move from these small diagrammatic models into fairly large scale models that would have a high level of tectonic and material articulation in close proximity to the idea of internal occupation and experience of architectural place. This final iteration mainly aimed at a discussion of occupational narrative that would have the translative memory of the filmic narrative (Figures 10-12). 
Vol. 2, No. $1 \quad$ Kara: Representation vs. Ideation in Architectural Design Process
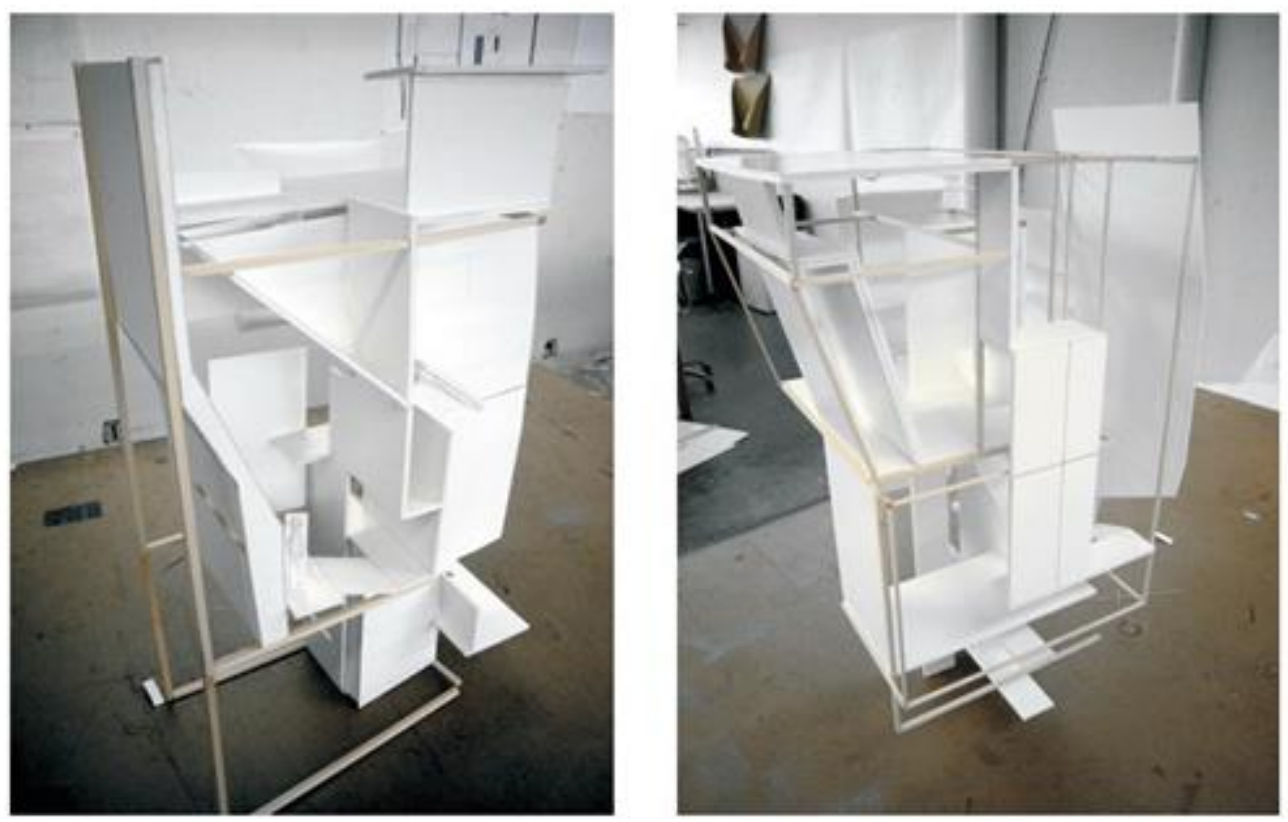

Figure 9. Thinking the Architecture-to-Come: Scalar Shift and Tectonic Refinement

Source: Author
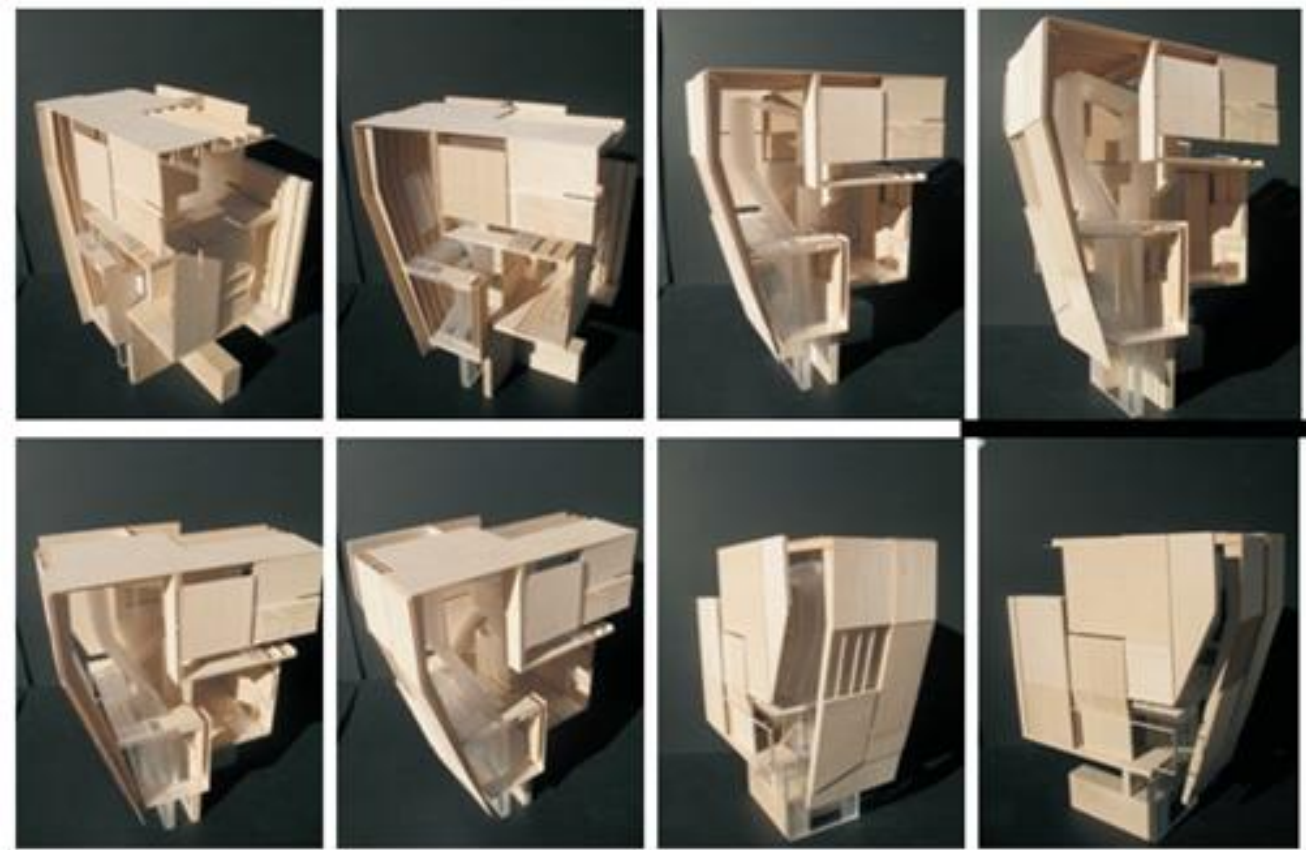

Figure 10. Final Iterations 1

Source: Author 

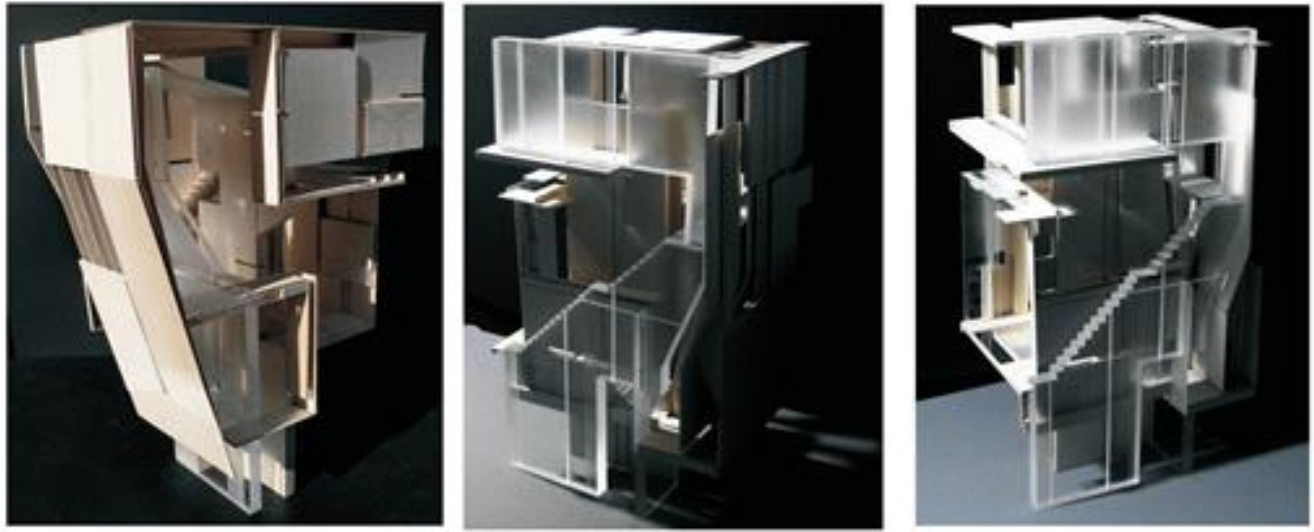

Figure 11. Final Iterations 2

Source: Author
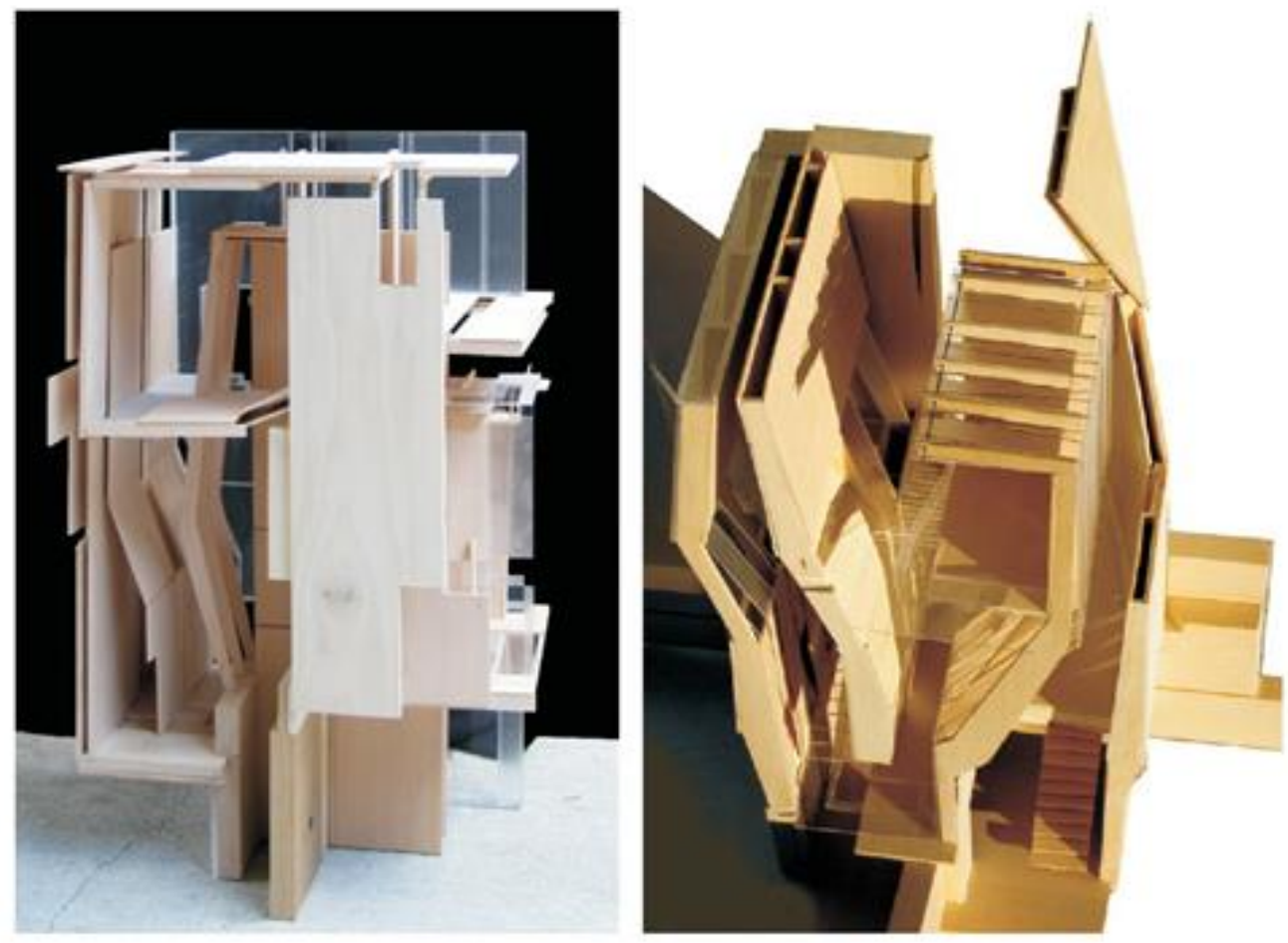

Figure 12. Final Iterations 3

Source: Author

Having studied the scalar shift in a series of models with fairly muted materiality (Figure 9), we went back to the interpretative diagrams, and the movie again, to resolve the final tectonic and material decisions that would construct place-events generated through our readings of the filmic narrative. While one concern was how the subject occupies the spatio-tectonic result in terms of a phenomenal subject-object relation, the overall construct was also mainly a social vessel for subject-subject relations (Figures 13-18). At the intersection of the phenomenal and social, the constructs formulated place- 
Vol. 2, No. $1 \quad$ Kara: Representation vs. Ideation in Architectural Design Process

events that were neither the filmic nor the architectural as we knew them prior to this exercise.
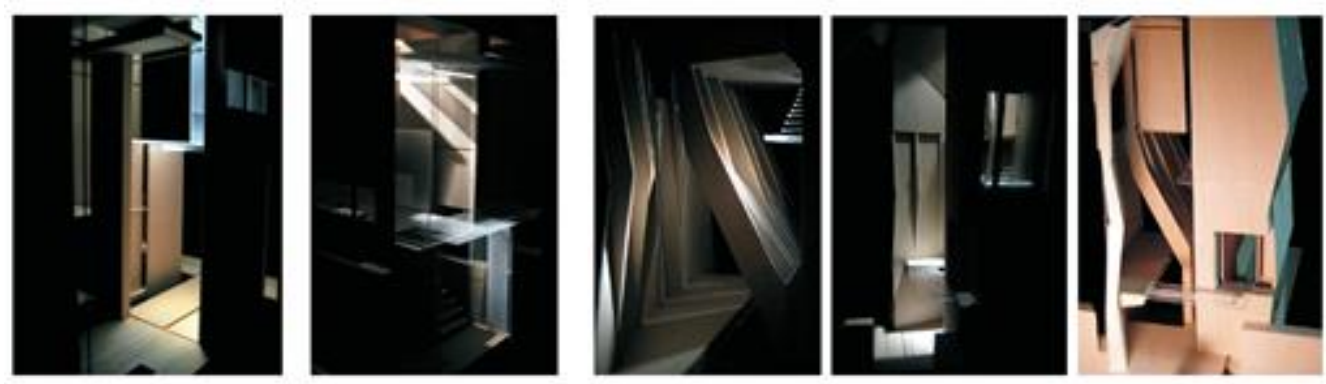

Figure 13. Occupational Narratives 1: Hide and Reveal Source: Author
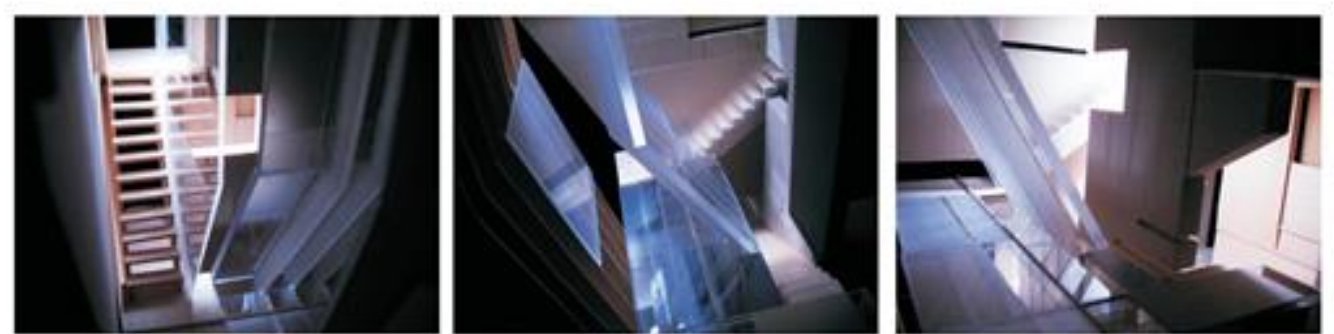

Figure 14. Occupational Narratives 2: Light as Movement Source: Author
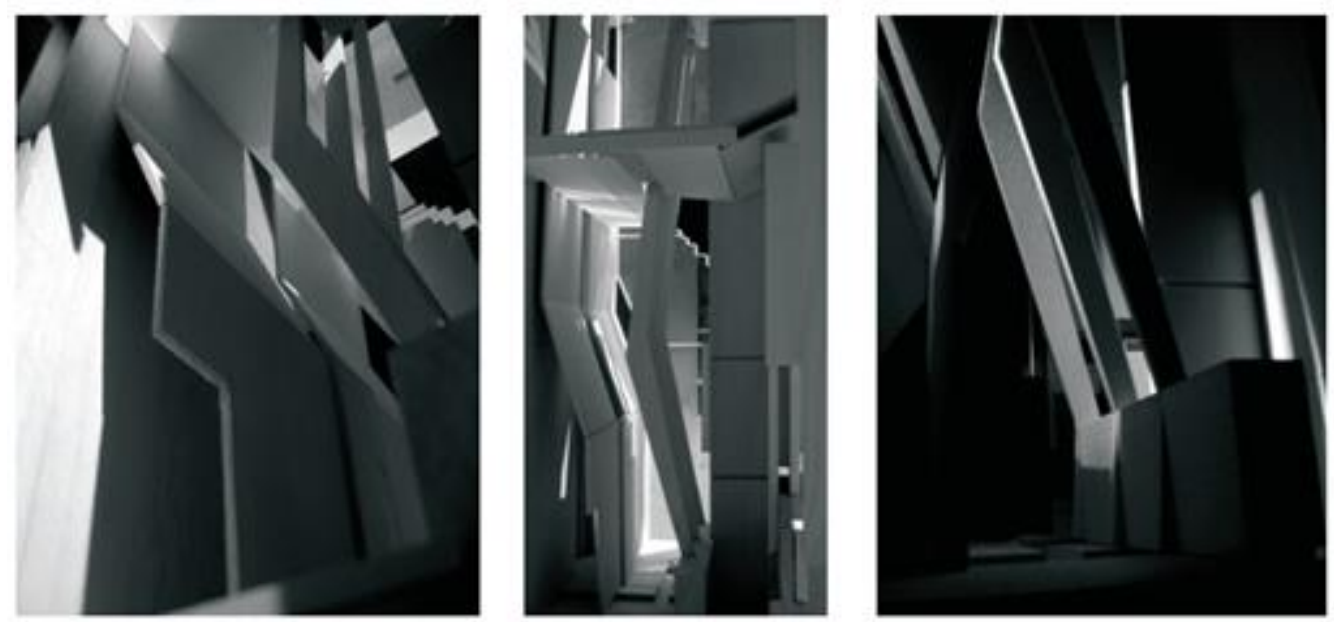

Figure 15. Occupational Narratives 3: Light and Gravity Source: Author 


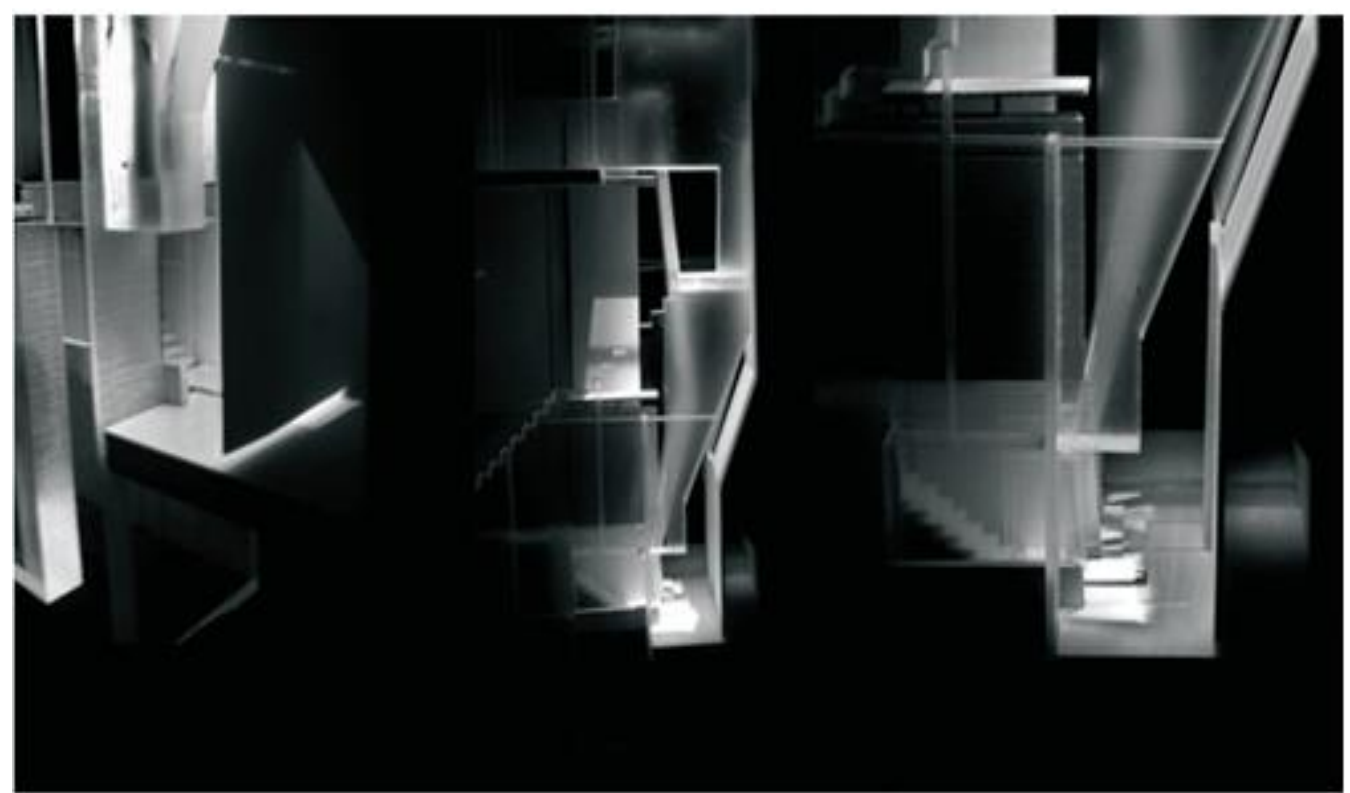

Figure 16. Occupational Narratives 4: The Space of Light Source: Author

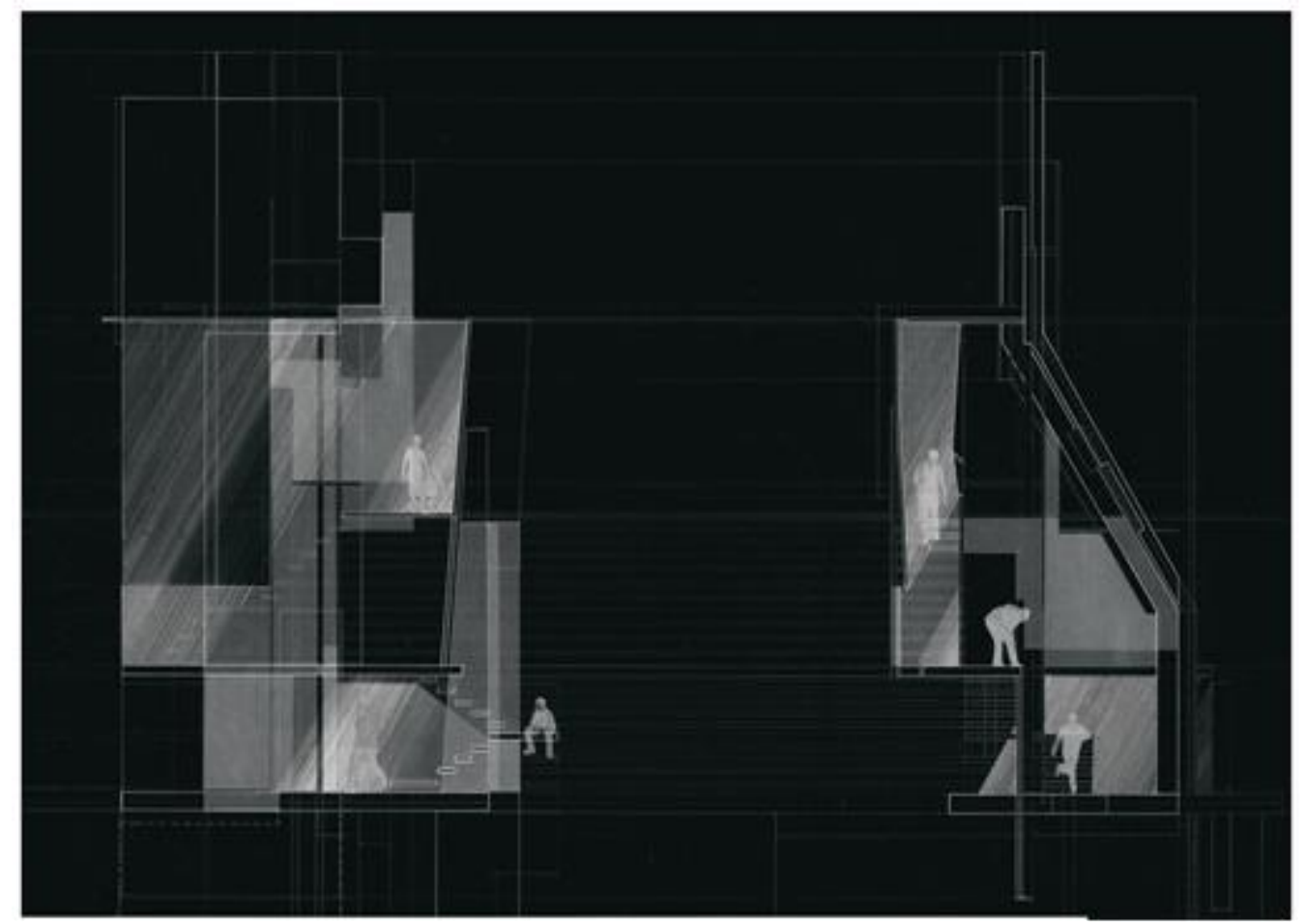

Figure 17. Occupational Narratives 5: The Social Vessel-Communication Source: Author 


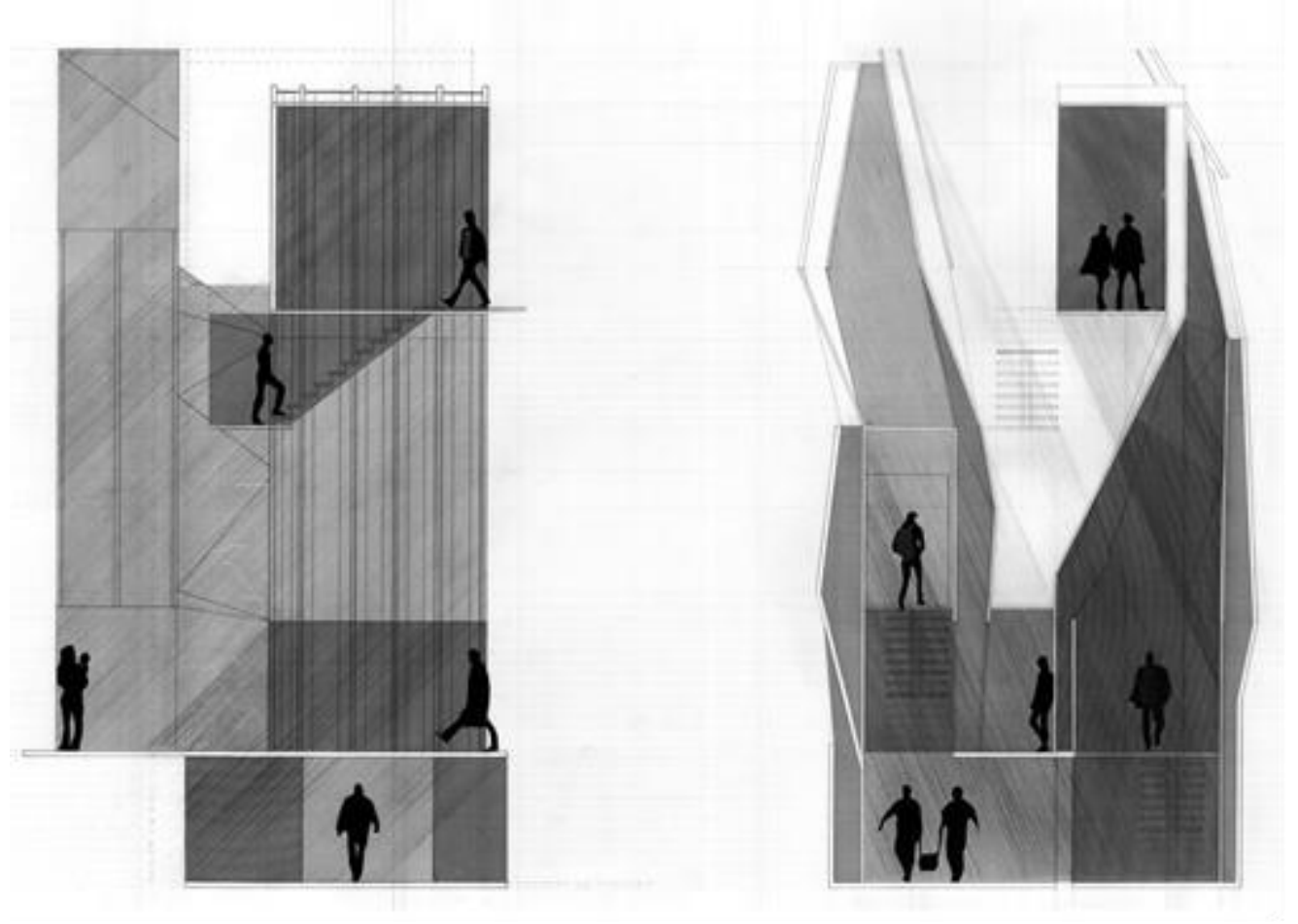

Figure 18. Occupational Narratives 6: The Social Vessel - Visibility

Source: Author

Beyond using the filmic narrative as a structural/symbolical analogue for architecture, beyond a metaphorical translation between the film and architectural space, this exercise through its intuitive steps shows the possibilities of using cultural catalysts in meaningful ways that contribute to our understanding of the nature of place making in the contemporary society not only as a distinct cultural modality but in its embeddedness within other modes of cultural experience. This view is important in order for a healthy assessment of the value of cultural narratives in the making of architecture. While architecture is inevitably tied to other cultural narratives in the way it sets and regulates specific life conditions in the texture of life, to make these cultural narratives authoritative in architectural experience, or rather, to make these cultural narratives a necessary condition for experiencing architecture, it misses the agency of architectural making in culture as a speculative act of thinking and making that forms new pieces of reality through imaginative interpretations that project possibilities out of the existing texture of culture. ${ }^{4}$

4. Gunter Bandmann, Early Medieval Architecture as Bearer of Meaning (New York: Columbia University Press, 2005), 19. The view that takes cultural narratives as the necessary condition for the meaningfulness of architectural experience is well exemplified in the writings of Marco Frascari and Dalibor Vesely. Underlying both authors' thinking on the value and role of cultural narratives is what Gunter Bandmann calls "a wider nexus of ideas" as the source of any meaningful making in the broader space of culture. "To say that a work of art has a meaning is to point to something, to some arrangement within a wider nexus of ideas that transcends the material and formal organization of the work of art. The realm of artistic is transcended in that the work of art comes to be understood as a metaphor, as a representative, 


\section{Architectural Image: The Metaphor, the Poet, and the Impact}

When poetry makes use of a metaphor, it makes use of first-person knowledge of things as we apprehend them in our experience. Hence, it draws upon a field of experience, which is the language of image, the language of space, to make a significance that is not visible, in the descriptive language of contexts of daily discourses, before its utterance in the poetic metaphor. By juxtaposing distant things as to their particular qualities apprehended in firstperson experience, the poetic metaphor achieves a new significance. Along with the tendency to understand every communication on the basis of language, it could be said that such language of image and space are themselves known through familiarity within a system of representations: by being exposed to certain kinds of things, types of things, along with their associated meanings which are embedded in them in time. While this may be one way of understanding the notion of image as a collective entity, in the familiarity of lived culture, our relationship to lived phenomena cannot be reduced to this way of understanding the language of image and space. When Paul Ricoeur examines the poetic metaphor in terms of a new predicament in language, he pursues the question of new meaning in terms of a semantic innovation (1987). ${ }^{5}$ Such semantic innovation, which also innervates the descriptive language itself, can only be possible if the poetic metaphor is preceded by an original seeing. ${ }^{6}$ The poetic metaphor is an intervention in our experience of the world rather than a representation of something already existing, and waiting to be articulated. ${ }^{7}$ New meaning in art happens differently from new meaning in descriptive language. A new construct in descriptive language is a new particular brought under a general significance when the occasion arises within a context of meaning. Wollheim underlines that 'a mature speaker can produce a new sentence of his language on the appropriate occasion, and other speakers can understand it immediately, though it is equally new to them' (59$60)$. It can be said that the poetic metaphor is not only a new utterance in the language, but it is also its own occasion. ${ }^{8}$ It occasions the significance it points at within itself, beyond established contexts of meaning, as the significance is

as the material emanation of something else". See also Marco Frascari, "The Tell-the-Tale Detail," in Theorizing a New Agenda for Architecture: An Anthology of Architectural Theory 1965-1995, ed. Kate Nesbitt (New York: Princeton Architectural Press, 1996), 448-453 and Marco Frascari, Monsters of Architecture: Anthropomorphism in Architectural Theory (Rowman and Littlefield, 1991), and Dalibor Vesely, Architecture in the Age of Divided Representation: The Question of Creativity in the Shadow of Production (London and Cambridge: The MIT Press, 2004).

5. Paul Ricoeur, "On Interpretation," in After Philosophy: End or Transformation, ed. Kenneth Baynes, James Bohman, and Thomas McCarthy (London and Cambridge: The MIT Press, 1987), 357-380.

6. Gaston Bachelard, The Poetics of Space, trans. Maria Jolas (Boston: Beacon Press, 1994), xx. "The poet, in the novelty of his images, is always the origin of language."

7. Ibid., xxiii. I think this is also what Bachelard has in mind when he underlines "the psychological action of a poem."

8. Ibid. "Here expression creates being." 
not read off, ${ }^{9}$ but experienced in the multiplicity of reverberations between juxtaposed phenomena. ${ }^{10}$ This is also how art contributes to the making of our world, ${ }^{11}$ as it offers new objects of intentionality, new contents in the form of new experiences rather than representing already existing significances. A poetic metaphor, to express what it says, relies on our first-person relation to things as they are phenomenally apprehended by us beyond their general significances in our language. Even if it depends on the possibility of our seeing and hearing of its reverberations, we cannot easily say that they were there and poetry simply appropriated them in language. This would be reducing the imaginative act of poetry to the possibilities of language. In a poet's hands, language is a tool to reveal and express an original seeing which is not within the possibilities of the prior state of language.

And if the poet uses the language of known images to express what is notyet-seen, or not-yet-felt, and expresses them in the familiarity of the words of a spoken language, architecture has the power to create those very experiences which the poet only has access through his imaginative operation on the significances of the words. Thinking with known images in the words is a poet's job: to express meaning by using the power of images, of the things, events known through first-person experience. Architecture creates those images that the poet thinks through words. If poetry is using a language of images, architecture is constructing that language again and again in the act of making lived space.

\section{Conclusions}

When a cultural narrative is to be embedded in architecture, there is still an act of original translation into language of form, language of space, hence the language of phenomenal consciousness of place. Even if we do not know the narrative, there is still something we see and feel in the experience of architecture: the comportment of the object as a made thing on a site with a certain way of housing the body. There are certain relations between components and parts of a work that are supposed to be apprehended in order to judge the work as a unity. Architecture cannot receive its power to communicate from the narrative, it is the narrative itself that needs architecture to be 'visualized', 'lived through'. Architecture might be said to be more

9. Richard Wollheim, Art and Its Objects, $2^{\text {nd }}$ ed. (Cambridge: Cambridge University Press, 1980), 60. "We see or experience the emotion in the work of art, we do not 'read it off'."

10. Bachelard, The Poetics of Space, xxii. "The resonances are dispersed on the different planes of our life in the world, while the repercussions invite us to give greater depth to our own existence. In the resonance we hear the poem, in the reverberations we speak it, it is our own. The reverberations bring about a change of being."

11. Wollheim, Art and Its Objects, 61. Wollheim underlines that "art is not iconic in the strongest sense". In a linguistic sense, "a work of art would threaten to be little more than an assemblage or compilation of pre-existing items". Ibid., 101. For him it would be to ignore art's contribution to human experience if it is held that "it merely appropriates, or annexes to itself, feelings, thoughts, attitudes, that are already in existence." 
significant for a community if it tells a collective story as such, but this cannot account for its original power to make things visible in its own modality as a lived spatio-temporal event by itself. The lived space of architecture does not have to issue from general meanings embedded in the collectivity to be an experience of significance in its own right. Even if meaningfulness as such cannot be attributed simply to individual making, as also is the case with poetry, as it always is born into and sits in a larger space of culture, to say that architecture needs a narrative to become non-trivial is the depreciation of architecture's own formative powers, to create images by the way it orders space and time and life in its phenomenal existence, which cannot be reduced to a representational existence. If we are to understand architecture as metaphor, and if we do not want architecture to drop away as the bearer of a message, we have to acknowledge the distance between the reference, the message, and how architecture mediates it. The phenomenal unity of the work cannot be that of the reference, but it is how it is interpreted by the way of its emplotment in architecture. Thus, it is one thing to say that the unity of architectural work as a spatio-temporal experience is the unity of a unifying idea and another to say that this unifying idea has to be a known significance in the collective consciousness of society in order for art or architecture to make sense.

\section{Bibliography}

Bachelard, Gaston. The Poetics of Space. Translated by Maria Jolas. Boston: Beacon Press, 1994.

Bandmann, Gunter. Early Medieval Architecture as Bearer of Meaning. New York: Columbia University Press, 2005.

Frascari, Marco. "The Tell-the-Tale Detail." In Theorizing a New Agenda for Architecture: An Anthology of Architectural Theory 1965-1995, 448-453. Edited by Kate Nesbitt. New York: Princeton Architectural Press, 1996.

. Monsters of Architecture: Anthropomorphism in Architectural Theory. Rowman and Littlefield, 1991.

Pallasmaa, Juhani. "The Geometry of Feeling: A Look at the Phenomenology of Architecture." In Theorizing a New Agenda for Architecture: An Anthology of Architectural Theory 1965-1995, 448-453. Edited by Kate Nesbitt. New York: Princeton Architectural Press, 1996.

Ricoeur, Paul. "On Interpretation." In After Philosophy: End or Transformation, 357380. Edited by Kenneth Baynes, James Bohman, and Thomas McCarthy. London and Cambridge: The MIT Press, 1987.

Stravinsky, Igor. Poetics of Music in the Form of Six Lessons. Cambridge: Harvard University Press, 1947.

Vesely, Dalibor. Architecture in the Age of Divided Representation: The Question of Creativity in the Shadow of Production. London and Cambridge: The MIT Press, 2004.

Wollheim, Richard. Art and Its Objects, $2^{\text {nd }}$ ed. Cambridge: Cambridge University Press, 1980. 
